\title{
Deacetylated Sp1 improves $\beta$-glycerophosphate-induced calcification in vascular smooth muscle cells
}

\author{
ZIHAO ZHANG ${ }^{1}$, XINYU ZHANG ${ }^{1}$, CHENGWEI WANG $^{1}$, PENG ZHOU $^{2}$, JIE XIAO $^{1}$, \\ HUI ZHENG ${ }^{1}$, LEI WANG ${ }^{1}$, SENBO YAN ${ }^{1}$, YUE ZHANG ${ }^{1}$ and XIAOPING JI ${ }^{1}$ \\ ${ }^{1}$ Department of Cardiology, The Key Laboratory of Cardiovascular Remodeling and Function Research, \\ Chinese Ministry of Education, Chinese National Health Commission and Chinese Academy of \\ Medical Sciences, The State and Shandong Province Joint Key Laboratory of Translational Cardiovascular \\ Medicine, Qilu Hospital of Shandong University, Jinan, Shandong 250012; ${ }^{2}$ Department of Cardiology, \\ State Key Laboratory of Cardiovascular Disease, Fuwai Hospital, National Center for Cardiovascular Diseases, \\ Chinese Academy of Medical Sciences and Peking Union Medical College, Beijing 100037, P.R. China
}

Received November 26, 2020; Accepted June 30, 2021

DOI: $10.3892 / \mathrm{etm} .2021 .10586$

\begin{abstract}
The aging of the population has led to an annual increase in the incidence of vascular calcification (VC). Specific protein 1 (Sp1) is a transcriptional activator that serves an important role in VC. The deacetylation of transcription factors represses their binding to the promoters of downstream genes, thereby causing their downregulation. The present study aimed to investigate the role of deacetylated $\mathrm{Sp} 1$ in the development of VC. In the present study, western blotting and immunoprecipitation (IP) were performed to detect the protein levels of acetylated Sp1. Western blotting and immunofluorescence staining were used to analyze phenotypic switching in vascular smooth muscle cells (VSMCs). Alizarin red S, alkaline phosphatase (ALP) activity and calcium content assays were used to assess calcium deposition in VSMCs. Western blotting, flow cytometry, TUNEL
\end{abstract}

Correspondence to: Dr Xiaoping Ji, Department of Cardiology, The Key Laboratory of Cardiovascular Remodeling and Function Research, Chinese Ministry of Education, Chinese National Health Commission and Chinese Academy of Medical Sciences, The State and Shandong Province Joint Key Laboratory of Translational Cardiovascular Medicine, Qilu Hospital of Shandong University, 107 West Wenhua Road, Jinan, Shandong 250012, P.R. China E-mail: jixiaoping@sdu.edu.cn

Abbreviations: $\quad \mathrm{VC}, \quad$ vascular calcification; $\mathrm{Sp}$, specific protein $1 ; \beta$-GP, $\beta$-glycerophosphate; BMP2, bone morphogenetic protein 2; VSMC, vascular smooth muscle cell; PTM, post-translational modification; $\alpha$-SMA, $\alpha$-smooth muscle actin; Bcl-2, B-cell lymphoma 2; Runx2, runt-related transcription factor 2; Bax, Bcl-2-associated X protein; RT, room temperature; $\mathrm{NC}$, normal control; ALP, alkaline phosphatase; ChIP, chromatin immunoprecipitation

Key words: deacetylation, Sp1, vascular calcification, apoptosis, BMP2, phenotype switching staining and caspase 3 activity assay were used to evaluate apoptosis of VSMCs. Chromatin immunoprecipitation (ChIP) assay was used to detect Sp1 binding to the BMP2 promoter. The results indicated that, in a $\beta$-glycerophosphate $(\beta-\mathrm{GP})$-induced VSMC calcification model, the level of acetylated Sp1 was increased. Western blotting and immunofluorescence staining results showed that, compared with the Sp1 overexpression group (Sp1-WT), deacetylated Sp1 (Sp1-K704A) downregulated the expression of osteogenic markers runt-related transcription factor 2 (Runx2) and bone morphogenetic protein 2 (BMP2), and upregulated the expression of contraction marker $\alpha$-smooth muscle actin ( $\alpha$-SMA) and calponin 1 . In addition, deacetylated Sp1 also reduced the ALP activity and calcium content of calcified VSMCs, and the Alizarin red S assay revealed that the calcium crystallization of Sp1-K704A group was markedly decreased. Western blotting, flow cytometry, TUNEL staining and caspase-3 activity assay were detected to indicate that the $\mathrm{B}$-cell lymphoma 2 (Bcl-2)/Bcl-2-associated $\mathrm{X}$ protein ratio was increased, and caspase-3 activity and the apoptotic rate of VSMCs were decreased, in the Sp1-K704A group, as compared with the Sp1-WT group. ChIP assay revealed that Sp1 binding to the BMP2 promoter was downregulated in the Sp1-K704A group, compared with that in theSp1-WT group. In conclusion, a deacetylated mutant of Sp1 decreased Sp1 binding to the BMP2 promoter, thus decreasing apoptosis, phenotypic switching and calcium deposition in calcified VSMCs. This finding may indicate potential therapeutic targets for $\mathrm{VC}$.

\section{Introduction}

Vascular calcification (VC), a prevalent complication of atherosclerosis, aging, chronic kidney disease and diabetes, is a major contributor to the high morbidity and mortality observed in cardiovascular diseases (1). Based on the location of the lesion, $\mathrm{VC}$ is classified into either intimal and medial calcification (2). Vascular medial calcification is not a passive calcium salt deposition process, but rather an active osteogenic process regulated by vascular smooth muscle cells (VSMCs) in 
the medial layer (3). Accumulating evidence demonstrates that $\mathrm{VC}$ is associated with cell apoptosis, calcified matrix exosome release and osteogenic phenotype transformation of VSMCs, the apoptosis of which influences VC initiation and osteogenic transformation in VSMCs, is a key event of VC (4).

Specific protein $1(\mathrm{Sp} 1)$ is a transcriptional activator extensively involved in life-sustaining activities, such as cell cycle, proliferation, differentiation, chromatin remodeling and DNA damage (5-9). Sp1 C-terminal-specific zinc fingers can bind to promoters of target genes rich in GC boxes and participate in transcriptional regulation of target genes (10). A recent study revealed that $\mathrm{Spl}$ accelerated the process of VC by promoting VSMC phenotypic transformation or accelerating apoptosis (11). Sp1 is widely involved in the basic expression of several genes, including genes associated with early embryonic development, and regulates cell proliferation and differentiation (12). The knockout of Sp1 during embryonic growth and development is invariably fatal in the $\mathrm{Sp1}^{-/-}$C57BL/6 mouse model (12), underlining its crucial role in sustaining basic life activities. Therefore, it is particularly important to regulate the pro-calcifying effect of Sp1 without affecting its expression level. Hence, the present study focused on the post-translational modifications (PTMs) of Sp1, with the aim of helping to identify potential therapeutic targets.

PTM is a process of chemical modification in proteins, which alters their structure and function (13). Excluding phosphorylation, lysine acetylation is the most widely known PTM and it not only enhances transcription by attenuating interactions between histones and chromatin, but also promotes the transcriptional activity of non-histone transcription factors (14). A previous study revealed that the acetylation of Sp1 occurs in its DNA-binding domain and upregulates the expression of downstream genes (15). Deacetylation, as opposed to acetylation, is associated with transcriptional repression (16).

The aim of the present study was to explore whether deacetylated $\mathrm{Sp} 1$ regulates calcification by inhibiting phenotypic switching and apoptosis in VSMCs and, if so, to further determine the potential molecular mechanisms.

\section{Materials and methods}

Cell culture and calcification model. Primary rat VSMCs were extracted from thoracic aortic arteries of male Wistar rats ( 8 weeks; weight, $160 \pm 10 \mathrm{~g}$ ) using the tissue explant adherent method, as previously described (17). The rats were obtained from Charles River Laboratories, Inc. and kept in a climate-controlled room (temperature, $25 \pm 1^{\circ} \mathrm{C}$; relative humidity, 50-60\%) with free access to food and water and a 12-h light/dark cycle. All animal experimental protocols were approved by the Ethics Committee of Qilu Hospital of Shandong University. In short, the rats were euthanized by an overdose of pentobarbital (>150 mg/kg; i.p.) until loss of limb reflexes.

Cells at passages 3-8 were used for experiments. VSMCs were incubated in high-glucose DMEM/Nutrient Mixture F-12 (Gibco; Thermo Fisher Scientific, Inc.) containing 10\% FBS (Gibco; Thermo Fisher Scientific, Inc.), $1 \%$ penicillin and $1 \%$ streptomycin (Gibco; Thermo Fisher Scientific, Inc.) at $37^{\circ} \mathrm{C}$ in a humidified incubator with $5 \% \mathrm{CO}_{2}$. The culture medium was replaced once per day in this way until harvesting after 3 days.
To induce calcification, confluent VSMCs were treated with $10 \mathrm{mmol} / 1 \beta$-glycerophosphate $(\beta-\mathrm{GP}$; cat. no. G9422; Merck KGaA) for $2-14$ days at $37^{\circ} \mathrm{C}$ (11). The culture medium containing $\beta$-glycerophosphate was replaced every 3 days. Cells without any treatment were used as the normal control (NC).

Western blotting. Western blotting was performed as previously described (11). Briefly, VSMCs were treated with $10 \mathrm{mmol} / 1 \beta$-GP for 3 days at $37^{\circ} \mathrm{C}$ and dissolved in RIPA buffer (Beyotime Institute of Biotechnology) after washing in cold PBS. The supernatant was centrifuged at $14,000 \mathrm{x}$ g at $4^{\circ} \mathrm{C}$ for $10 \mathrm{~min}$ to obtain total protein. Protein concentration was measured using a BCA protein assay kit (Beyotime Institute of Biotechnology). The proteins (30 $\mu \mathrm{g} /$ lane) were separated by 10-12\% SDS-PAGE and transferred to polyvinylidene fluoride membranes $(0.22 / 0.45 \mu \mathrm{m}$; EMD Millipore) which were then blocked at room temperature (RT) for $1 \mathrm{~h}$ in PBS-Tween-20 (PBS-T) solution containing 5\% skimmed milk. Primary antibodies against Sp1 (1:1,000; cat. no. NBP2-20460; Novus Biologicals, LLC), BMP2 (1:1,000; cat. no. ab214821; Abcam), $\alpha$-smooth muscle actin ( $\alpha$-SMA) $(1: 1,000$; cat. no. ab7817; Abcam), calponin 1 (1:1,000; cat. no. 17819; Cell Signaling Technology, Inc.), Bcl-2 (1:1,000; cat. no. ab196495; Abcam), runt-related transcription factor 2 (Runx2) (1:1,000; cat. no. 12556; Cell Signaling Technology, Inc.), $\beta$-actin (1:1,000; cat. no. 3700; Cell Signaling Technology, Inc.), Bax (1:1,000; cat. no. 2772; Cell Signaling Technology, Inc.) were incubated with membranes overnight at $4{ }^{\circ} \mathrm{C}$. On day 2 , the membranes were extensively washed with Tris-buffered saline with $0.1 \%$ Tween-20 and incubated with a horseradish peroxidase-conjugated goat anti-rabbit immunoglobulin $\mathrm{g}$ (IgG) secondary antibody (1:5,000; cat. no. SA00001-9; ProteinTech Group, Inc.) or goat anti-mouse IgG secondary antibody (1:5,000; cat. no. SA00001-8; ProteinTech Group, Inc.) for $1.5 \mathrm{~h}$ at RT. Protein signals were visualized using an Amersham Imager 600 electrochemiluminescence instrument (Cytiva) and semi-quantified using ImageJ Software (version 1.48; National Institutes of Health).

Immunoprecipitation $(I P)$. VSMCs were treated with $10 \mathrm{mmol} / 1 \beta$-GP for 3 days at $37^{\circ} \mathrm{C}$ and dissolved in RIPA buffer (Beyotime Institute of Biotechnology) after washing in cold PBS. The supernatant was centrifuged at $14,000 \mathrm{x} \mathrm{g}$ at $4^{\circ} \mathrm{C}$ for $10 \mathrm{~min}$ to obtain whole-cell extracts. $400 \mu \mathrm{l}$ whole-cell extracts $\left(2 \times 10^{6}\right.$ cells $)$ were preincubated with $25 \mu 1$ magnetic beads (cat. no. HY-K020; MedChemExpress) on a rotator for $2 \mathrm{~h}$ at $4^{\circ} \mathrm{C}$ to clear non-specific bead binding. Following magnetic separation, the extracts were incubated with anti-Sp1 antibody (1:100; cat. no. NBP2-20460; Novus Biologicals, LLC) on a rotator overnight at $4^{\circ} \mathrm{C}$. The protein-antibody mixture was then re-incubated with $40 \mu 1$ magnetic beads and cleaned with PBS with $0.5 \%$ Triton X-100 (PBST) on a rotator for $4 \mathrm{~h}$ at $4^{\circ} \mathrm{C}$. After washing four times in PBS-T, the magnetic beads were separated magnetically. The proteins that remained and had bound to the magnetic beads were released by boiling in $1 X$ SDS-PAGE loading buffer. The isolated proteins were then analyzed. Acetyl-lysine antibody (1:1,000; cat. no. sc-81623; Santa Cruz Biotechnology, Inc.) was used 
to detect the levels of acetyl-Sp1 using western blotting as aforementioned.

Plasmid transfection. A previous study showed that the acetylation site of Sp1 is at Lys703 in human epidermoid carcinoma cells (A431) and that mutating lysine 703 (K703) to alanine (A) leads to deacetylation of Spl (18). In addition, following the alignment of the genomic sequence between humans and rats through the GenBank database on the NCBI website (http://www.ncbi.nlm.nih.gov/), as previously described (19), it was found that the acetylation site of Sp1 is at Lys704 (K704) in rats. Next, Sp1 overexpression plasmid (pCMV; Sp1-WT), Sp1 point mutant (K704A) plasmid (pCMV; Sp1-K704A) and control plasmid (pCMV; control plasmid) were synthesized by Shanghai Genechem Co. Ltd. SMCs $\left(1 \times 10^{5}\right.$ cells $\left./ \mathrm{ml}\right)$ were seeded in 6-well plates. In total, $6 \mu \mathrm{g}$ plasmid was transfected into VSMCs with $6 \mu \mathrm{l}$ Micropoly-transfecter Cell Reagent (Micropoly) for $24 \mathrm{~h}$ at $37^{\circ} \mathrm{C}$ and used for subsequent experiments. For in vitro analysis, $48 \mathrm{~h}$ after cell transfection, the cells were treated with $10 \mathrm{mmol} / \mathrm{l} \beta$-GP for $2-14$ days.

Immunofluorescence staining. VSMCs $\left(1 \times 10^{5}\right.$ cells $\left./ \mathrm{ml}\right)$ were seeded in 24-well climbing slice culture plates treated with $10 \mathrm{mmol} / \mathrm{l} \beta$-GP for 3 days at $37^{\circ} \mathrm{C}$ following plasmid transfection. They were then fixed in $4 \%$ paraformaldehyde for $1 \mathrm{~h}$ at RT. Following washing with PBS, cells were permeabilized using $0.5 \%$ Triton $\mathrm{X}-100$ for $10 \mathrm{~min}$ at RT. Next, cells were washed with PBS and blocked with $5 \%$ bovine serum albumin (cat. no. A8850-5; Beijing Solarbio Science \& Technology Co., Ltd.) for $30 \mathrm{~min}$ at RT. The cells were then double-stained with primary antibodies against BMP2 (1:100; cat. no. ab214821; Abcam) and $\alpha$-SMA (1:100; cat. no. 48938; Cell Signaling Technology, Inc.) in PBS overnight at $4^{\circ} \mathrm{C}$. On day 2, following extensive washing with PBS, cells were incubated with Alexa Fluor 488-conjugated goat anti-mouse (1:200; cat. no. ZF-0511; Beijing Zhongshan Golden Bridge Biotechnology Co., Ltd.) or Alexa Fluor 594-conjugated goat anti-rabbit (1:200; cat. no. ZF-0516; Beijing Zhongshan Golden Bridge Biotechnology Co., Ltd.) for $1 \mathrm{~h}$ at RT. Following staining with DAPI for $10 \mathrm{~min}$ at $37^{\circ} \mathrm{C}$, cells were viewed by fluorescence microscopy (magnification, x200; Nikon Eclipse NI-E; Nikon Corporation) and analyzed using ImageJ Software (version 1.48; National Institutes of Health).

Calcium staining. Calcium staining was performed as previously described (17). Briefly, calcification induction was performed by $10 \mathrm{mmol} / \mathrm{l} \beta$-GP for 12 days at $37^{\circ} \mathrm{C}$ following plasmid transfection, VSMCs were washed with PBS and fixed in $70 \%$ ethanol for $1 \mathrm{~h}$ at RT. Following rinsing with PBS, VSMCs were exposed to $1 \mathrm{mg} / \mathrm{ml}$ Alizarin red S solution $(\mathrm{pH} 4.2)$ in the dark for another $1 \mathrm{~h}$ at RT. Images were captured using an inverted motorized microscope (magnification, $\mathrm{x} 40$; Nikon Ti-E; Nikon Corporation).

Calcium deposition detection, ALP activity and caspase-3 activity assay. VSMCs were treated with $10 \mathrm{mmol} / 1 \beta$-GP for 6 days at $37^{\circ} \mathrm{C}$ following plasmid transfection and dissolved in RIPA buffer (Beyotime Institute of Biotechnology) after washing in cold PBS. The supernatant was centrifuged at
$14,000 \times \mathrm{g}$ at $4^{\circ} \mathrm{C}$ for $10 \mathrm{~min}$ to obtain whole-cell extracts. The calcium content was determined using the Calcium Assay kit at RT (cat. no. C004-2; Nanjing Jiancheng Bio-engineering Institute Co., Ltd.), and ALP and caspase-3 activities were detected using an ALP assay kit at RT (cat. no. P0321; Beyotime Institute of Biotechnology) and caspase-3 activity assay kit at $37^{\circ} \mathrm{C}$ (cat. no. C1116; Beyotime Institute of Biotechnology), respectively. The testing of calcium content, ALP and caspase-3 activities were performed according to the manufacturers' instructions. The results were then normalized to protein concentrations measured using an enhanced BCA protein assay kit (cat. no. P0010; Beyotime Institute of Biotechnology).

TUNEL assay. Apoptosis in calcified VSMCs was measured using an In Situ Cell Death Detection kit at RT, TMR red (cat. no. 12156792910; Roche Diagnostics), following the manufacturer's instructions. In brief, VSMCs $\left(1 \times 10^{5}\right.$ cells $\left./ \mathrm{ml}\right)$ were incubated in a 24 -well plate and treated with $10 \mathrm{mmol} / \mathrm{l}$ $\beta$-GP for 3 days at $37^{\circ} \mathrm{C}$ following plasmid transfection. The steps to fix and permeabilize cells were the same as those for immunofluorescence. Calcified VSMCs were then stained using TUNEL dyes for a minimum of $60 \mathrm{~min}$ at $37^{\circ} \mathrm{C}$. Following DAPI staining for $10 \mathrm{~min}$ at $37^{\circ} \mathrm{C}$, TUNEL-positive VSMCs were manually counted via fluorescence microscopy (magnification, x200; Nikon Eclipse NI-E; Nikon Corporation).

Annexin V/propidium iodide double-staining. VSMCs $\left(1 \times 10^{5}\right.$ cells $\left./ \mathrm{ml}\right)$ were incubated in a 6 -well plate and treated with $10 \mathrm{mmol} / 1 \beta$-GP for 3 days at $37^{\circ} \mathrm{C}$ following plasmid transfection. Following the manufacturer's instructions, Annexin V/propidium iodide double-staining was performed using an Annexin V-FITC Apoptosis Detection kit at RT (cat. no. 556547; BD Pharmingen), and apoptotic cells were detected using BD FACSCalibur (BD Biosciences) and analyzed using FlowJo software (version 7.6; FlowJo LLC).

Chromatin immunoprecipitation (ChIP) assay. VSMCs $\left(2 \times 10^{7}\right.$ cells $\left./ \mathrm{ml}\right)$ were treated with $10 \mathrm{mmol} / \mathrm{l} \beta$-GP for 3 days at $37^{\circ} \mathrm{C}$ following plasmid transfection. ChIP assay was performed using SimpleChIP ${ }^{\circledR}$ Plus Enzymatic ChIP kit at RT (cat. no. 9005; Cell Signaling Technology, Inc.), according to the manufacturer's instructions. Anti-sp1 antibody (1:50; cat. no. NBP2-20460; Novus Biologicals, LLC) was used to bind chromatin-bound proteins for $24 \mathrm{~h}$ at $4^{\circ} \mathrm{C}$. The primers used to amplify the fragments containing the BMP 2 promoter were as follows: BMP2 forward, 5'-TTACACTCAGCCGGG ACGC-3' and reverse, 5'-GAACACCTCCCCCTCGGA-3'. The PCR products were analyzed on $2 \%$ agarose gel and then visualized using an electrochemiluminescence instrument (Bio-Rad Laboratories, Inc.). ChIP signal was normalized to total input. A positive control (Anti-Histone H3; 1:50; cat. no. 9005; Cell Signaling Technology, Inc.) and a negative control (normal IgG; 1:50; cat. no. 9005; Cell Signaling Technology, Inc.) were employed for each immunoprecipitation.

Statistical analysis. Each experiment was performed $>3$ times independently. Data are presented as the mean \pm SEM. GraphPad Prism 8.0 (GraphPad Software, Inc.) was used for statistical analysis. Unpaired Student's t-test was used for 
A

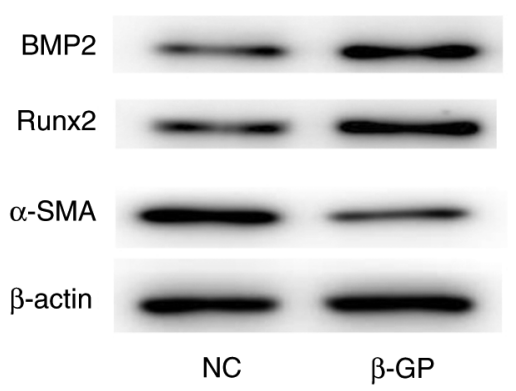

B

IP
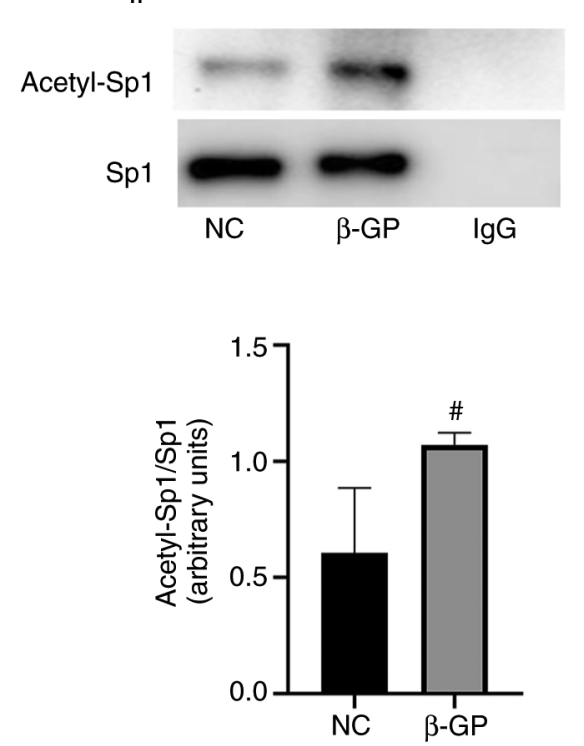
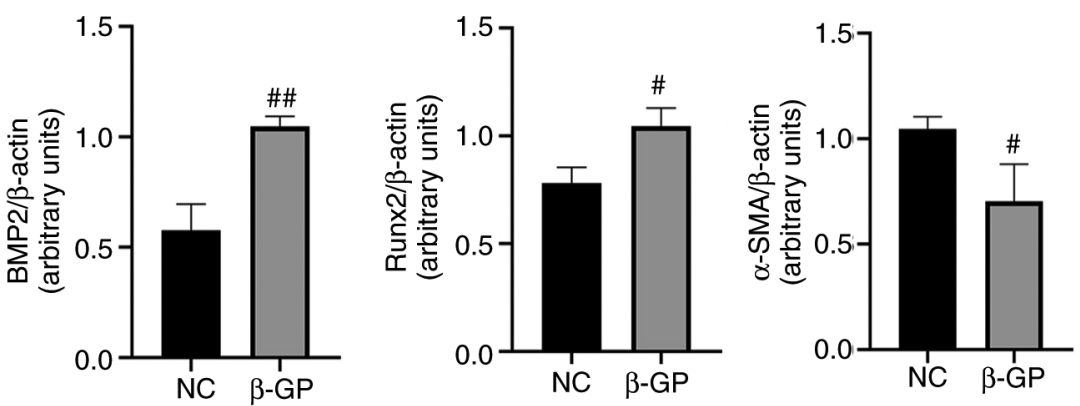

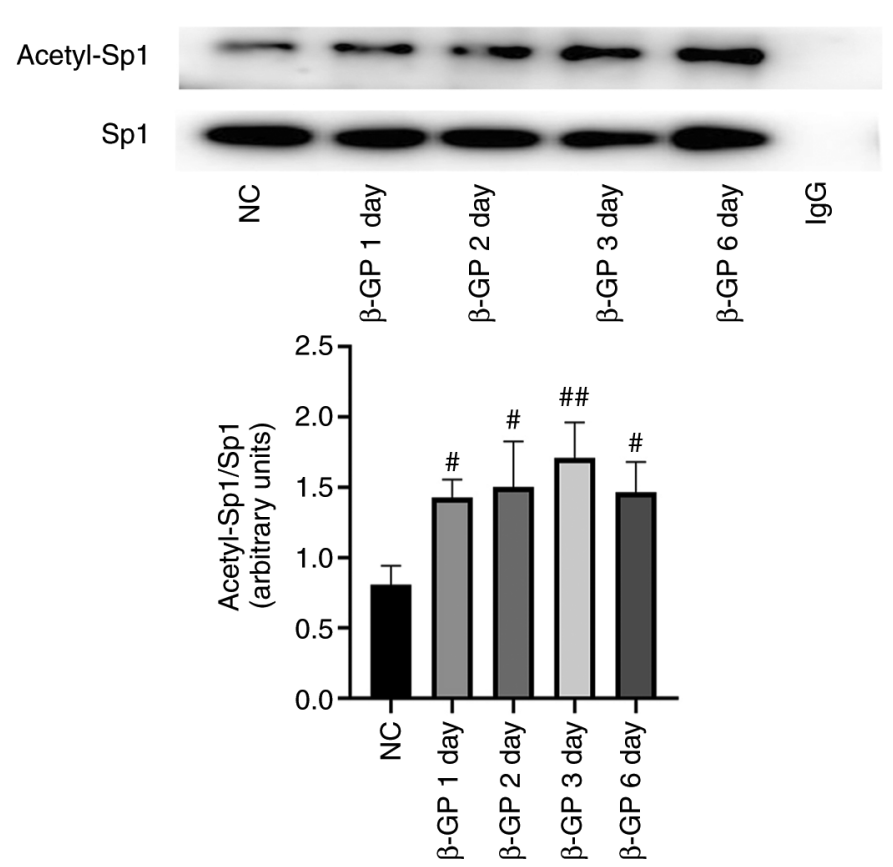

Figure 1. Acetylated Sp1 expression levels are higher in calcified VSMCs. (A) BMP2, Runx2, $\alpha$-SMA and calponin 1 expression levels were measured by western blotting and normalized to $\beta$-actin. (B and C) Acetylated Sp1 expression was measured by IP and normalized to Sp1. Data are presented as the mean \pm SEM. $\mathrm{n}=3 .{ }^{~} \mathrm{P}<0.05 ;{ }^{\# \prime} \mathrm{P}<0.01$ vs. NC group. NC group, normal cultured VSMCs; $\beta$-GP group, $\beta$-glycerophosphate-induced VSMCs; IP, immunoprecipitation; Sp1, specific protein 1; VSMCs, vascular smooth muscle cells; BMP2, bone morphogenetic protein 2; Runx2, runt-related transcription factor 2; $\alpha$-SMA, $\alpha$-smooth muscle actin; $\beta$-GP, $\beta$-glycerophosphate.

comparisons between two groups, and one-way ANOVA, followed by Tukey's post hoc test for comparisons among multiple groups. $\mathrm{P}<0.05$ was considered to indicate a significantly significant different.

\section{Results}

Expressionlevelsofacetylated Spl areincreasedin $\beta$-GP-treated VSMCs. As previously described, VSMCs were treated with $\beta$-GP for $72 \mathrm{~h}$ at $37^{\circ} \mathrm{C}$ to induce calcification (17). Western blotting was performed to assess the calcification of VSMCs, and it was found that the expression levels of the osteogenic markers BMP2 and Runx 2 were upregulated and those of $\alpha$-SMA, a marker of the contractile phenotype of VSMCs, was reduced (Fig. 1A; P<0.05). Next, the expression levels of acetylated Sp1 in calcified VSMCs was investigated. The IP results showed that, compared with the control group, the expression levels of acetylated Spl were increased in a time-dependent manner in the calcification group (Fig. 1B and C; $\mathrm{P}<0.05$ ).
Sp1 acetylation site is at K704 in rat VSMCs. Next, Sp1 K704A mutant plasmid was constructed to mimic the deacetylation status of Sp1, and then Sp1-WT plasmid and Sp1-K704A mutant plasmid were transfected into VSMCs. At $48 \mathrm{~h}$ from infection, the acetylation levels of Sp1 were examined. As shown by western blotting (Fig. 2A; P<0.05), protein levels of Sp1 remained unchanged following negative control plasmid transfection, but were higher following Sp1 WT and K704A mutant plasmid transfection, as compared with the NC. The IP results revealed that acetylated Sp1 levels were markedly reduced by $\mathrm{Sp} 1 \mathrm{~K} 704 \mathrm{~A}$ plasmid, as comparison with plasmid Sp1 WT plasmid (Fig. 2B; P<0.05).

Spl deacetylation ameliorates calcium deposition and phenotype switching in calcified VSMCs. Following transfection with Sp1-WT and Sp1-K704A plasmids, calcification was induced in VSMCs by $\beta$-GP for $3-12$ days at $37^{\circ} \mathrm{C}$. As shown in Fig. 3A-C, Alizarin red S staining, ALP activity assay and calcium content assay $(\mathrm{P}<0.05)$ indicated that 
A
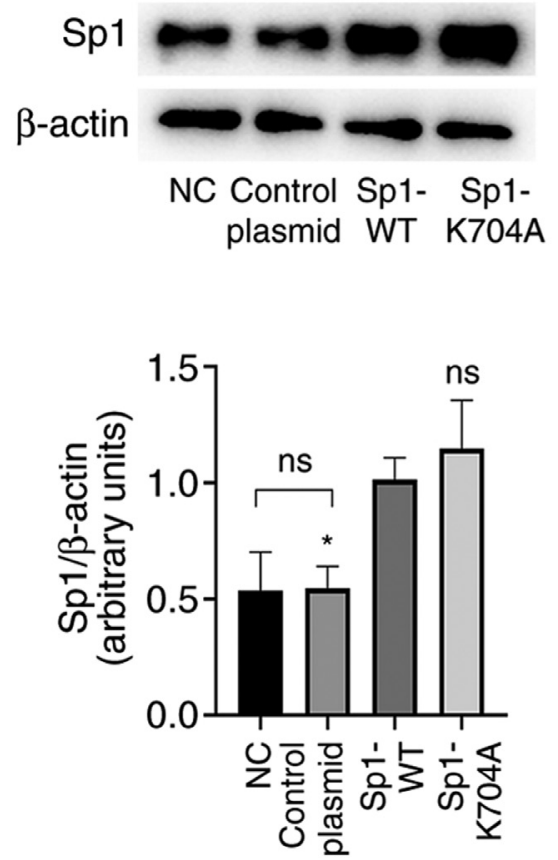

$\mathrm{B}$

IP
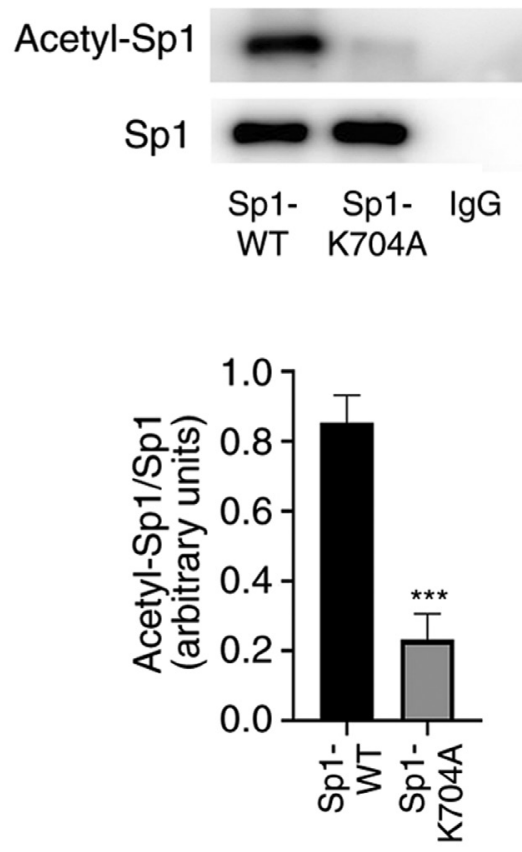

Figure 2. Sp1 acetylation site is located at K704A in rat VSMCs. (A) Sp1 protein levels were measured by western blotting and normalized to $\beta$-actin. (B) Acetylated Sp1 were measured by IP and normalized to Sp1. Data are expressed as the mean $\pm \mathrm{SEM}$. n=3. ${ }^{*} \mathrm{P}<0.05$; ${ }^{* * *} \mathrm{P}<0.001$ vs. Sp1-WT group. ns, not significant; NC, normal control; control plasmid, VSMCs transfected with negative control plasmid; Sp1-WT, VSMCs transfected with Sp1-WT plasmid; Sp1-K704A, VSMCs transfected with Sp1-K704A plasmid; Sp1, specific protein 1; IP, immunoprecipitation; VSMCs, vascular smooth muscle cells; WT, wild-type.

compared with the Sp1 overexpression group, deacetylated Sp1 clearly inhibited calcium deposition in calcified VSMCs. Moreover, using western blot analysis (Fig. 4A; $\mathrm{P}<0.05$ ) and immunofluorescence staining (Fig. 4B; $\mathrm{P}<0.05$ ), it was observed that the decreased levels of VSMC contractile markers $\alpha$-SMA and calponin 1 were rescued, while those of osteogenic markers Runx2 and BMP2 were suppressed. Simultaneously, it was observed that calcium deposition and phenotype switching were enhanced by Spl overexpression in the $\mathrm{Sp1}$ overexpression group, as compared with the induced calcification group. The $\beta$-GP groups and NC were used as a reference to confirm the state of calcification and Sp1 overexpression in VSMCs, respectively.

Deacetylated Sp1 reduces apoptosis in calcified VSMCs. To investigate the role of deacetylated $\mathrm{Sp} 1$ on apoptosis, Annexin V-PI flow cytometry (Fig. 5C; P<0.05) and TUNEL analysis (Fig. 5D; $\mathrm{P}<0.05$ ) were performed. The number of apoptotic VSMCs was markedly reduced by deacetylated Sp1 (Sp1-K704A). In addition, the expression levels of the apoptosis-related protein Bax and the anti-apoptotic protein Bcl-2 were determined via western blotting. It was revealed that, compared with the Sp1 overexpression (Sp1-WT) group, the $\mathrm{Bcl}-2 / \mathrm{Bax}$ ratio was increased in the Sp1-K704A group (Fig. 5A; $\mathrm{P}<0.05$ ). Caspase-3 activity assay showed that deacetylated Sp1 significantly reduced the activity of caspase3 to inhibit VSMCs apoptosis (Fig. 5B; $\mathrm{P}<0.05$ ).

Deacetylated Sp1 inhibits VSMC phenotype switching and apoptosis by decreasing Sp1 binding to BMP2 promoter.
Based on the aforementioned findings, the underlying mechanism mediating the protective role of deacetylated Sp1 in VSMC calcification was explored. Considerable evidence has demonstrated that BMP2 is not only involved in VSMC phenotype switching, but also in VSMC apoptosis $(20,21)$. Furthermore, in our previous study, it was revealed that $\mathrm{Sp} 1$ binding to BMP2 promoter was elevated in $\beta$-GP-induced calcified VSMCs (11). To determine whether deacetylated Sp1 regulated VC by inhibiting Sp1 binding activity to the BMP2 promoter, a ChIP assay was performed in $\beta$-GP-induced calcified VSMCs following plasmid transfection. As shown in Fig. 6A and B, it was observed that Sp1 binding to the BMP2 promoter was downregulated in the Sp1-K704A group compared with that in the Sp1 overexpression (Sp1-WT) group.

\section{Discussion}

The present study demonstrated that deacetylated Sp1 can significantly reverse the calcification of VSMCs. The levels of acetylated Sp1 were clearly increased by $\beta$-GP-induced calcification and altered depending the $\beta$-GP stimulation time. Following plasmid transfection conducted to interfere with the levels of acetylated Sp1, osteogenic transformation, calcium deposition and apoptosis of calcified VSMCs were improved. Deacetylated Sp1 was found to exert an anti-VC effect by downregulating the binding of $\mathrm{Sp} 1$ to the promoter of the target gene BMP2.

$\mathrm{VC}$ is recognized as a common vascular complication during chronic kidney disease (CKD), aging and diabetes 
A

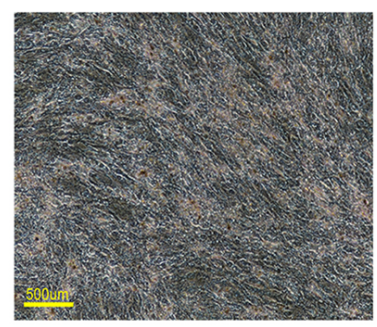

NC

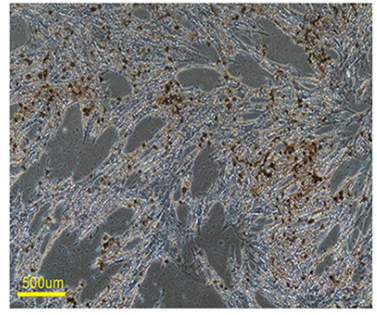

Sp1-WT+ $\beta-G P$

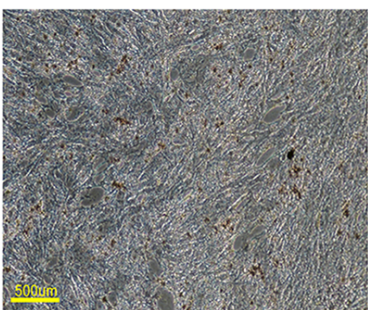

Control plasmid $+\beta-G P$

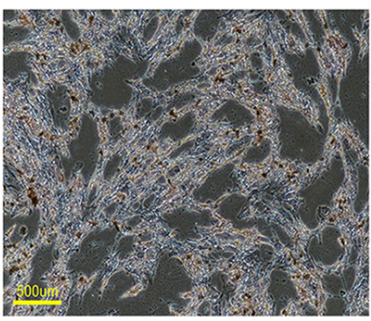

Sp1-K704A+ $\beta-G P$
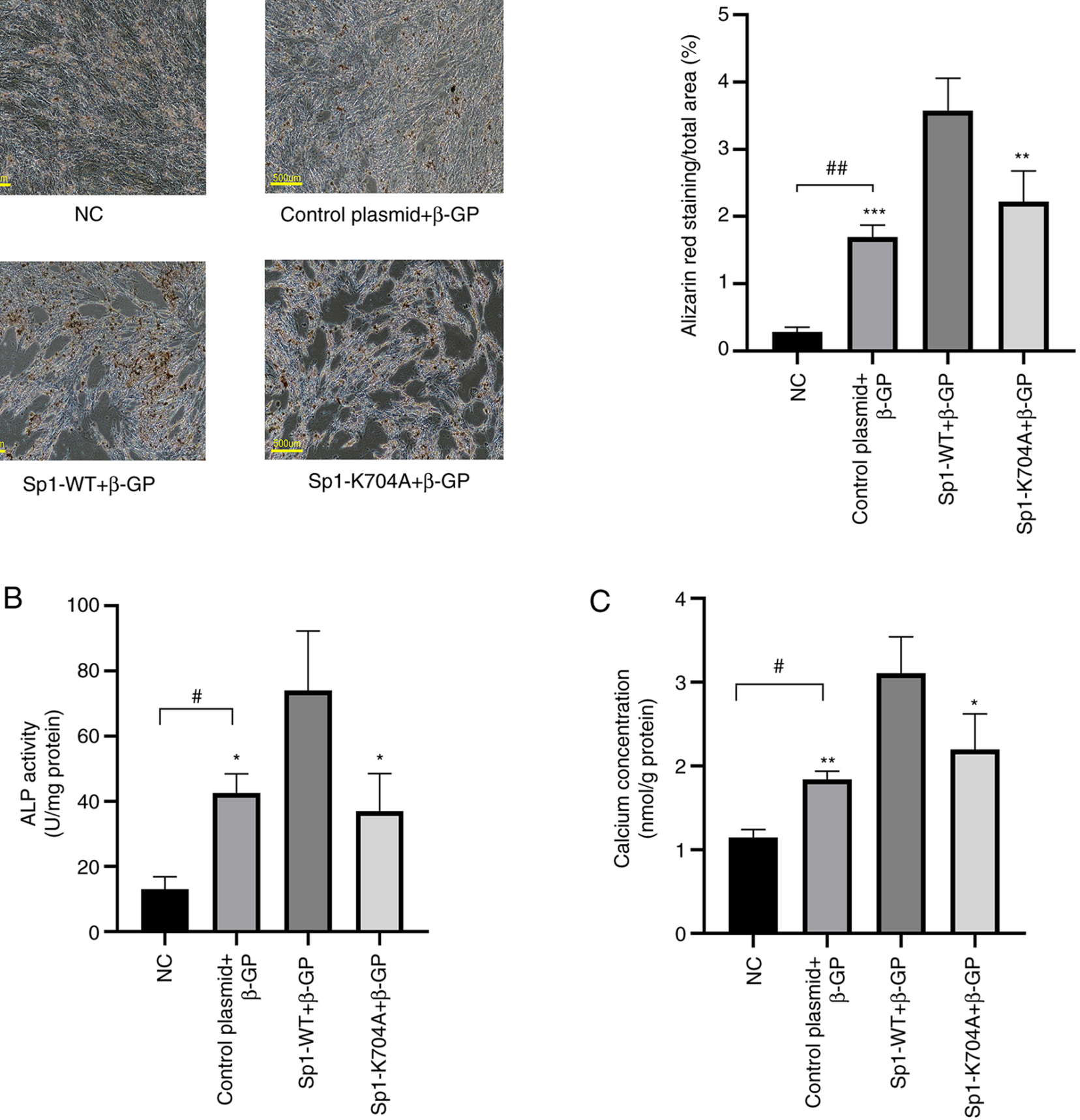

Figure 3. Deacetylated Sp1 ameliorates ALP activity and calcium deposition in calcified VSMCs. (A) Alizarin red S staining of VSMCs with $\beta$-GP induction for 12 days. Scale bar, $500 \mu \mathrm{m}$. (B) ALP activity and (C) calcium deposition in calcified VSMCs with $\beta$-GP induction for 6 days were measured and normalized to protein content for quantitative analysis. Data are presented as mean $\pm \mathrm{SEM} . \mathrm{n}=3 .{ }^{\sharp} \mathrm{P}<0.05 ;{ }^{\# \#} \mathrm{P}<0.01$ vs. NC group; ${ }^{*} \mathrm{P}<0.05 ;{ }^{* * *} \mathrm{P}<0.01 ;{ }^{* * *} \mathrm{P}<0.001$ vs. Sp1-WT group. NC, normal control; control plasmid $+\beta$-GP, $\beta$-glycerophosphate-induced VSMCs transfected with negative control plasmid; Sp1-WT $+\beta$-GP, $\beta$-glycerophosphate-induced VSMCs transfected with Sp1-WT plasmid; Sp1-K704A + $\beta$-GP, $\beta$-glycerophosphate-induced VSMCs transfected with Sp1-K704A plasmid; NC, normal control; ALP, alkaline phosphatase; VSMCs, vascular smooth muscle cells; $\beta$-GP, $\beta$-glycerophosphate; WT, wild-type.

mellitus. The selection of different $\mathrm{VC}$ models is based on the underlying disease. For example, glycation end-products (AGEs) produced by diabetics are important calcification promoters, thus diabetes-associated $\mathrm{VC}$ is studied using a calcification model established by AGEs (22). Anti-aging genes, such as klotho and sirt1 are downregulated during calcification, so the $\mathrm{VC}$ model of aging is established by inhibiting the associated anti-aging genes (23). The high-phosphorus-induced VC model is established based on the perivascular high phosphorus environment in patients with CKD (24). Since VC is more widespread in patients with CKD and hyperphosphatemia-related VC is currently a hot research topic, a $\beta$-GP-induced VC model was selected to study CKD-related VC (25). A previous study reported that blocking the phenotypic transformation of VSMC is essential for the prevention and treatment of VC (26). Therefore, phenotypic transformation of VSMCs can be used as a reliable index for assessing VC.

$\mathrm{Sp1}$, a member of the Sp family (Sp1-Sp8), was found to be the key regulator in the proliferation and invasion of 
A
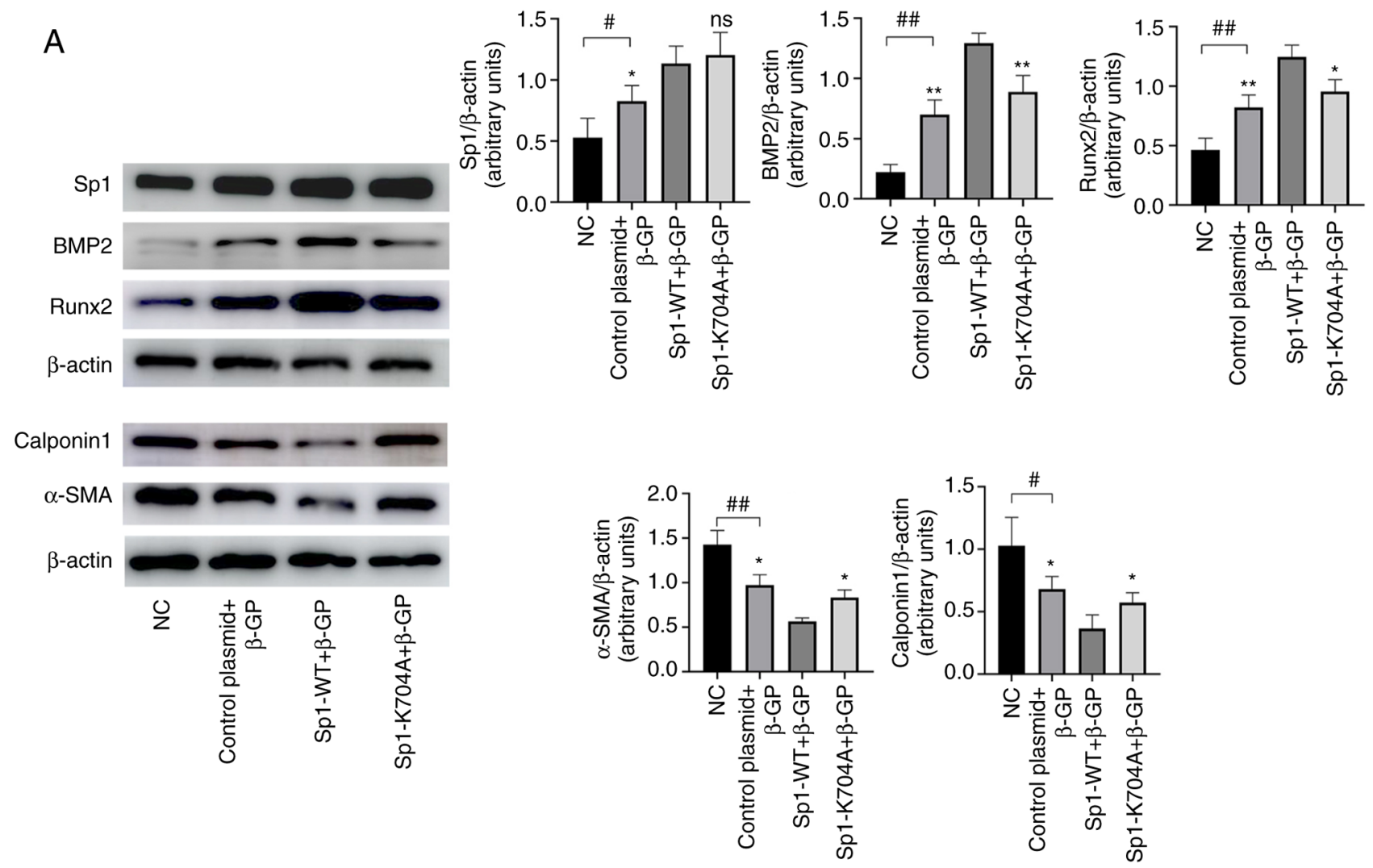

B
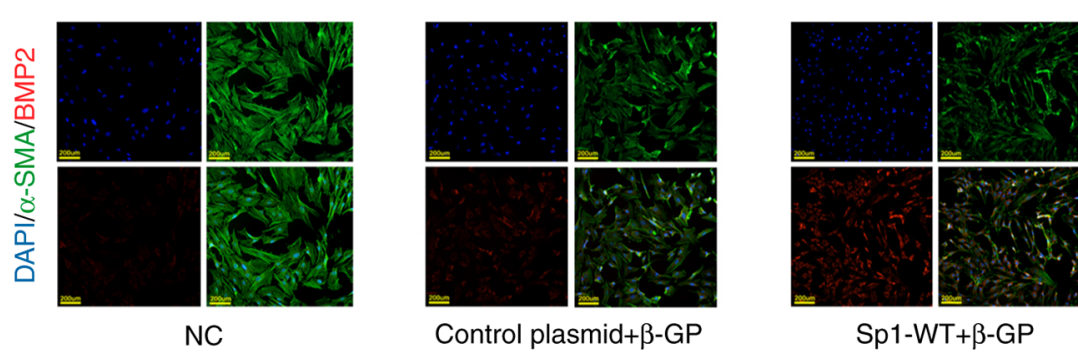

Sp1-WT+ + -GP

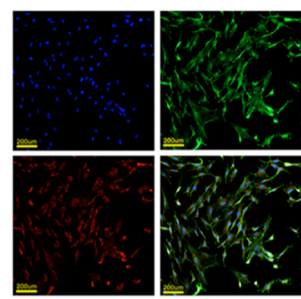

Sp1-K704A+ $\beta-G P$
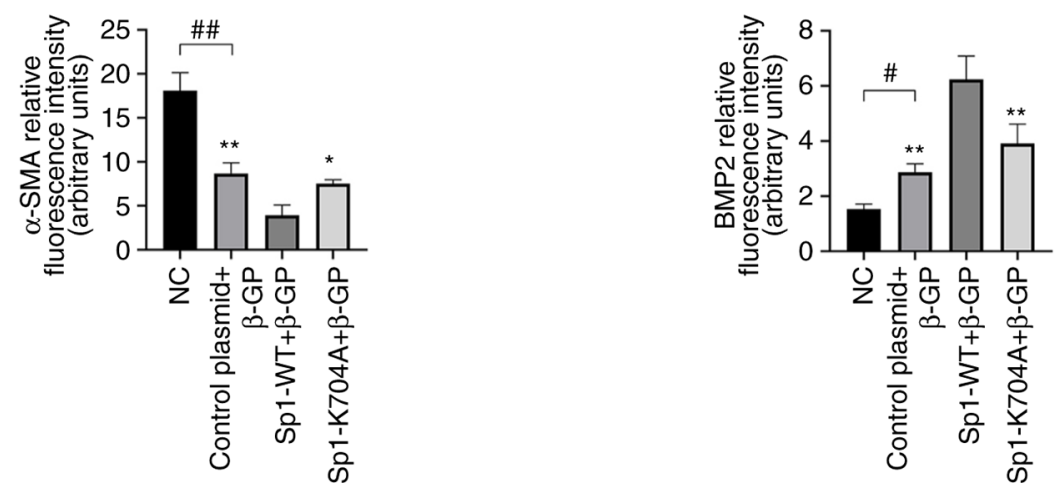

Figure 4. Deacetylated Sp1 ameliorates phenotypic switching in calcified VSMCs. Calcified VSMCs were induced by $\beta$-GP for 3 days after transfection. (A) Sp1, BMP2, Runx2, $\alpha$-SMA and calponin 1 protein expression was measured by western blotting and normalized to $\beta$-actin. (B) Immunofluorescence staining of BMP2 (red) and $\alpha$-SMA (green), Scale bar $=200 \mu \mathrm{m}$. Data are presented as the mean \pm SEM. $\mathrm{n}=3$. ${ }^{*} \mathrm{P}<0.05$; ${ }^{\# \prime} \mathrm{P}<0.01$ vs. NC group; ${ }^{*} \mathrm{P}<0.05$; ${ }^{* *} \mathrm{P}<0.01$ vs. Sp1-WT group; ns, $\mathrm{P}>0.05$. NC, normal control; control plasmid $+\beta$-GP, $\beta$-glycerophosphate-induced VSMCs transfected with negative control plasmid; Sp1-WT + $\beta$-GP, $\beta$-glycerophosphate-induced VSMCs transfected with Sp1-WT plasmid; Sp1-K704A + $\beta$-GP, $\beta$-glycerophosphate-induced VSMCs transfected with Sp1-K704A plasmid; NC, normal control; Sp1, specific protein 1; VSMCs, vascular smooth muscle cells; $\beta$-GP, $\beta$-glycerophosphate; BMP2, bone morphogenetic protein 2; Runx2, runt-related transcription factor 2; $\alpha$-SMA, $\alpha$-smooth muscle actin; WT, wild-type.

tumor cells $(9,27)$. Recently, the role of $\mathrm{Sp} 1$ in the occurrence and development of cardiovascular diseases was also investigated. Studies have suggested that Sp1 is involved in the regulation of myocardial cell apoptosis, myocardial fibrosis, inflammation, oxidative stress and vascular endothelial cell injury $(28,29)$. In our previous study, it was demonstrated that $\mathrm{Sp1}$ also regulates calcification and apoptosis in $\beta$-GP-induced calcified VSMCs, in which 
A

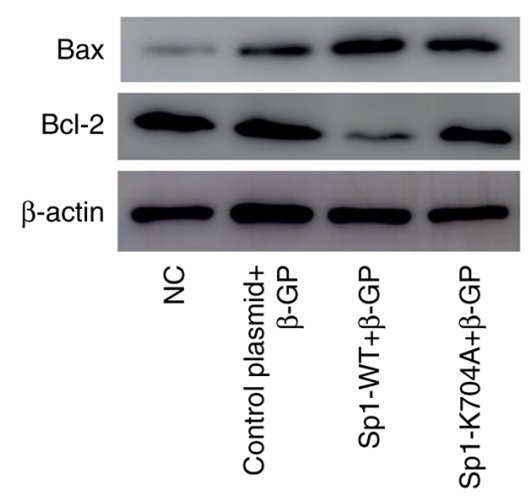

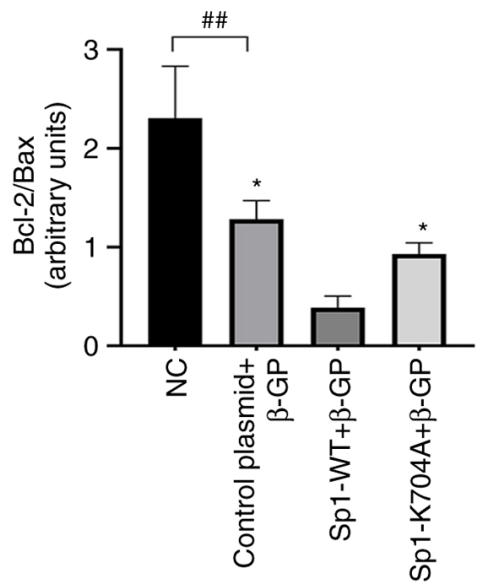

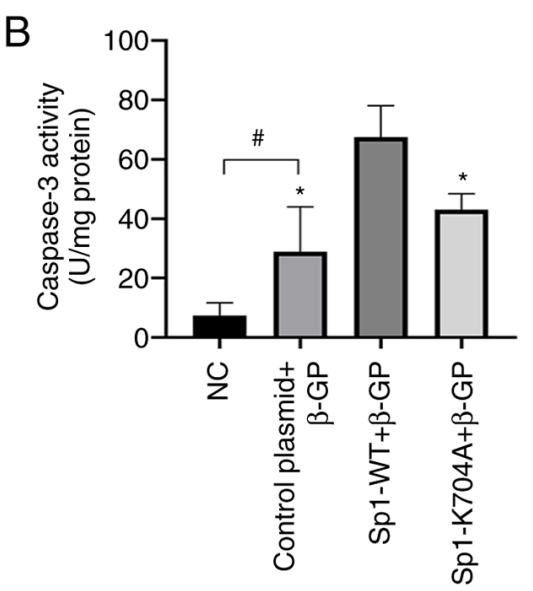

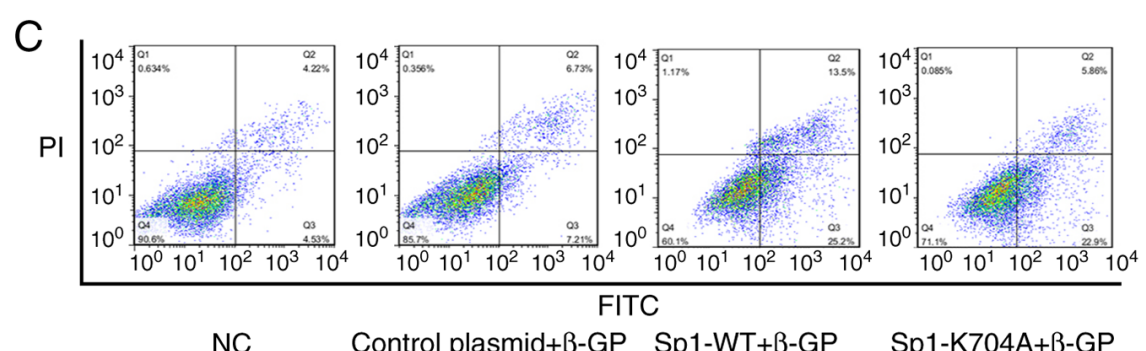
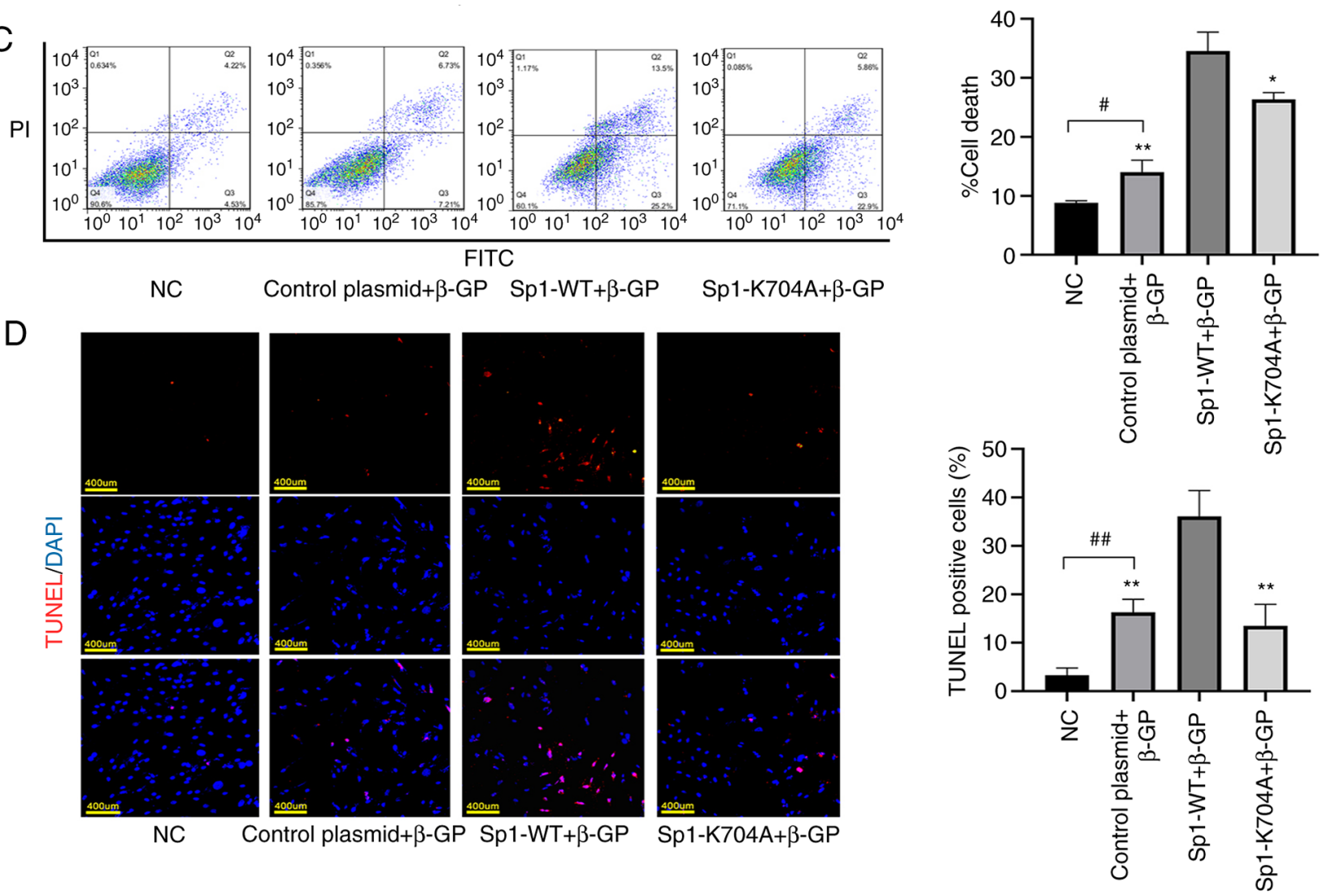

Figure 5. Deacetylated Sp1 reduces apoptosis in calcified VSMCs. Calcified VSMCs were induced by $\beta$-GP for 3 days after transfection. (A) Expression of apoptosis related-proteins Bcl-2 and Bax was measured by western blotting and the levels of Bcl-2/Bax were detected by densitometric analysis. (B) Caspase-3 activity was assessed using a caspase-3 activity assay kit. Apoptotic rate was determined by (C) TUNEL staining (Scale bar=400 $\mu$ m) and (D) Annexin V/propidium iodide double staining. Data are presented as the mean \pm SEM. $n=3$. ${ }^{\#} \mathrm{P}<0.05 ;{ }^{\# \#} \mathrm{P}<0.01$ vs. NC group; ${ }^{*} \mathrm{P}<0.05 ;{ }^{* *} \mathrm{P}<0.01$ vs. Sp1-WT group. NC, normal control; control plasmid + $\beta$-GP, $\beta$-glycerophosphate-induced VSMCs transfected with negative control plasmid; Sp1-WT + $\beta$-GP, $\beta$-glycerophosphate-induced VSMCs transfected with Sp1-WT plasmid; Sp1-K704A + $\beta$-GP, $\beta$-glycerophosphate-induced VSMCs transfected with Sp1-K704A plasmid; NC, normal control; Sp1, specific protein 1; VSMCs, vascular smooth muscle cells; $\beta$-GP, $\beta$-glycerophosphate; Bcl-2, B-cell lymphoma 2; Bax, Bcl-2-associated X protein; terminal deoxynucleotidyl transferase dUTP nick end labeling; WT, wild-type.

its pro-calcific role was performed by regulating BMP2 transcriptional activation (11). As the main promoter of medial calcification, BMP2 induces the expression of MSX2 and Runx2, which are key factors of VSMC phenotypic transformation (20). Sp1 is extensively involved in the basic expression of multiple genes, and the deletion of Sp1 is invariably fatal during fetal development (12). Therefore, it is important to downregulate the pro-calcified effect of Sp1 without affecting its expression level. Protein PTMs can increase the functional diversity of Sp1, therefore Sp1 PTMs were investigated in order to identify novel therapeutic targets in VC. The majority of the research conducted on Sp1 PTMs is on phosphorylation, but the level of phosphorylated Sp1 in calcified VSMCs exhibited non-significant changes compared with the NC group in our unpublished data (data not shown).

Histone acetylation serves an important role in gene regulation. A growing number of studies have suggested that, 
A

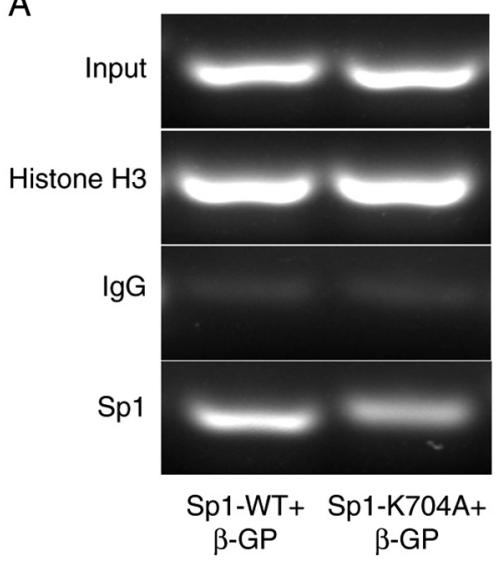

B

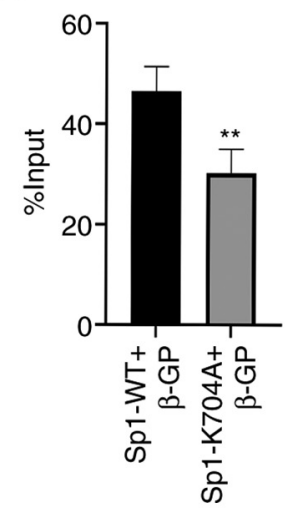

Figure 6. Deacetylated Sp1 inhibits VSMC phenotype switching and apoptosis by decreasing Sp1 binding activity to BMP2 promoter. Calcified VSMCs were induced by $\beta$-GP for 3 days after transfection. (A) ChIP assay. Nuclear DNA-protein complexes were extracted from VSMCs treated with $\beta$-GP precipitated with anti-Sp1 antibody. PCR was performed to amplify the region of the BMP2 promoter containing Not I fragment. (B) Semi-quantitative analysis of ChIP results. Data are presented as mean \pm SEM. $n=3 .{ }^{* *} \mathrm{P}<0.01$ vs. Sp1-WT group. Sp1-WT $+\beta-G P$ $\beta$-glycerophosphate-induced VSMCs transfected with Sp1-WT plasmid; Sp1-K704A + $\beta$-GP, $\beta$-glycerophosphate-induced VSMCs transfected with Sp1-K704A plasmid; Sp1, specific protein 1; VSMC, vascular smooth muscle cells; BMP2, bone morphogenetic protein $2 ; \beta$-GP, $\beta$-glycerophosphate; ChIP, chromatin immunoprecipitation; WT, wild-type.

besides histones, non-histone transcription factors can also be acetylated $(14,30)$. Acetylated $\mathrm{Sp1}$ has been reported to upregulate the binding activity to target genes during different pathological processes (31-33). However, to the best of our knowledge, no research has explored the association between acetylated Sp1 and VC. The present study revealed that the acetylated Sp1 expression is significantly elevated in calcified VSMCs. This result demonstrated that acetylated Sp1 promotes the development of VC. Therefore, it was suggested that inhibiting the acetylation of Sp1 may reduce VC. Hepp et al (34) reported that mutating $\mathrm{K} 703$ to A not only results in the deacetylation of Sp1, but also downregulates its transcriptional activity. Following genetic comparison, Sp1 K704A mutant plasmid was synthesized based on Sp1 overexpression to achieve the deacetylated state of Sp1 (deacetylated Sp1). In the present study, deacetylated Sp1 was found to suppress the expression of osteogenic markers and reduce calcium deposition in $\mathrm{VC}$, in line with our hypothesis. It was also observed that $\mathrm{Sp} 1$ overexpression promoted $\mathrm{VC}$, which, to the best of our knowledge, has not been explored in other studies.

Apoptosis, a type of programmed cell death, has been found to be associated with the initiation of VC $(35,36)$. Our previous study confirmed that, in addition to up-regulating BMP2 transcriptional activity, $\mathrm{Sp} 1$ also participated in VC-related apoptosis compared with the NC group (11). Of note, the apoptosis-promoting role of BMP2 in VSMCs was also reported in a previous study, which demonstrated that BMP2 promoted VSMC apoptosis via the Wnt/ $\beta$-catenin pathway (21). Therefore, it was hypothesized that deacetylated Sp1 may ameliorate VSMC apoptosis by repressing BMP2 transcription. In the present study, VSMC apoptosis was indeed shown to be ameliorated by inhibiting the acetylation of Sp1.

This was then confirmed by ChIP assay, which demonstrated that deacetylation of Sp1 decreased its binding to BMP2 promoter, in line with our hypothesis.

There were certain limitations to the present study. First, an acetyl-Sp1 overexpression plasmid could not be constructed, so the elevated level of acetylated Sp1 in calcified VSMCs was used to illustrate that acetylated $\mathrm{Sp} 1$ is responsible for the development of VC. Second, whether deacetylated Sp1 affects other vital activities regulated by $\mathrm{Sp} 1$, in addition to $\mathrm{VC}$, was not explored. Further research is therefore required to address these issues.

In conclusion, the present study provided strong evidence supporting that acetylated Sp1 promotes $\beta$-GP-induced VSMCs calcification. The deacetylation of Sp1 by Sp1-K704A plasmid prevents the calcification of VSMCs by inhibiting BMP2 transcription. These meaningful findings may provide new options for the treatment and prevention of $\mathrm{VC}$.

\section{Acknowledgements}

Not applicable.

\section{Funding}

The present study was supported by the National Natural Science Foundation of China (grant nos. 81873516, 81873522 and 81900444), the National Key Research and Development Program of Shandong Province (grant no. 2017YFC1308303), the Shandong Provincial Natural Science Foundation of China (grant no. ZR2019PH030) and the Clinical Research Center of Shandong University (grant no. 2020SDUCRCA009).

\section{Availability of data and materials}

The datasets used and/or analyzed during the present study are available from the corresponding author on reasonable request.

\section{Authors' contributions}

XPJ designed the study. ZHZ, XYZ, PZ, JX, HZ LW and YZ performed experiments. CWW and SBY performed the statistical analysis. ZHZ prepared the manuscript and performed the literature search. XPJ and XYZ have seen and can confirm the authenticity of the raw data. All authors have read and approved the final manuscript.

\section{Ethics approval and consent to participate}

All applicable international, national and/or institutional guidelines for the care and use of animals were followed. All procedures performed in studies involving animals were approved by the Ethics Committee of Qilu Hospital of Shandong University (Jinan, China).

\section{Patient consent for publication}

Not applicable.

\section{Competing interests}

The authors declare that they have no competing interests. 


\section{References}

1. Lanzer P, Boehm M, Sorribas V, Thiriet M, Janzen J, Zeller T, St Hilaire C and Shanahan C: Medial vascular calcification revisited: Review and perspectives. Eur Heart J 35: 1515-1525, 2014.

2. Demer LL and Tintut Y: Vascular calcification: Pathobiology of a multifaceted disease. Circulation 117: 2938-2948, 2008

3. Voelkl J, Lang F, Eckardt KU, Amann K, Kuro-O M, Pasch A, Pieske B and Alesutan I: Signaling pathways involved in vascular smooth muscle cell calcification during hyperphosphatemia. Cell Mol Life Sci 76: 2077-2091, 2019.

4. Durham AL, Speer MY, Scatena M, Giachelli CM and Shanahan CM: Role of smooth muscle cells in vascular calcification: Implications in atherosclerosis and arterial stiffness. Cardiovasc Res 114: 590-600, 2018.

5. Bajpai R and Nagaraju GP: Specificity protein 1: Its role in colorectal cancer progression and metastasis. Crit Rev Oncol Hematol 113: 1-7, 2017.

6. Leigh $\mathrm{O}$, Jane $\mathrm{G}$ and Constanze B: The role of the ubiquitously expressed transcription factor $\mathrm{Sp} 1$ in tissue-specific transcriptional regulation and in disease. Yale J Biol Med 89: 513-525, 2016.

7. Verrecchia F, Rossert J and Mauviel A: Blocking sp1 transcription factor broadly inhibits extracellular matrix gene expression in vitro and in vivo: Implications for the treatment of tissue fibrosis. J Invest Dermatol 116: 755-763, 2001.

8. Beishline K and Azizkhan-Clifford J: Sp1 and the "hallmarks of cancer'. FEBS J 282: 224-258, 2015.

9. Vizcaino C, Mansilla S and Portugal J: Sp1 transcription factor: A long-standing target in cancer chemotherapy. Pharmacol Ther 152: 111-124, 2015.

10. Solomon SS, Majumdar G, Martinez-Hernandez A and Raghow R: A critical role of Sp1 transcription factor in regulating gene expression in response to insulin and other hormones. Life Sci 83: 305-312, 2008

11. Zhang X, Li R, Qin X, Wang L, Xiao J, Song Y, Sheng X, Guo M and Ji X: Spl plays an important role in vascular calcification both in vivo and in vitro. J Am Heart Assoc 7: e007555, 2018.

12. Marin M, Karis A, Visser P, Grosveld F and Philipsen S: Transcription factor $\mathrm{Sp} 1$ is essential for early embryonic development but dispensable for cell growth and differentiation. Cell 89: 619-628, 1997.

13. Qian M, Yan F, Yuan T, Yang B, He Q and Zhu H: Targeting post-translational modification of transcription factors as cancer therapy. Drug Discov Today 25: 1502-1512, 2020.

14. Yang M, Zhang Y and Ren J: Acetylation in cardiovascular diseases: Molecular mechanisms and clinical implications. Biochim Biophys Acta Mol Basis Dis 1866: 165836, 2020.

15. Suzuki T, Kimura A, Nagai R and Horikoshi M: Regulation of interaction of the acetyltransferase region of p300 and the DNA-binding domain of Sp1 on and through DNA binding. Genes Cells 5: 29-41, 2000

16. Kwon DH, Ryu J, Kim YK and Kook H: Roles of histone acetylation modififiers and other epigenetic regulators in vascular calcifification. Int J Mol Sci 21: 3246, 2020.

17. Zhou P, Zhang X, Guo M, Guo R, Wang L, Zhang Z, Lin Z, Dong M, Dai H, Ji X and Lu H: Ginsenoside Rb1 ameliorates CKD-associated vascular calcification by inhibiting the Wnt/ $\beta$-catenin pathway. J Cell Mol Med 23: 7088-7098, 2019

18. Hung JJ, Wang YT and Chang WC: Spl deacetylation induced by phorbol ester recruits p300 to activate 12(S)-lipoxygenase gene transcription. Mol Cell Biol 26: 1770-1785, 2006.

19. Liu HL, Xin YF and Xun LY: Distribution, diversity, and activities of sulfur dioxygenases in heterotrophic bacteria. Appl Environ Microbiol 80: 1799-1806, 2014.

20. Yang P, Troncone L, Augur ZM, Kim SSJ, McNeil ME and Yu PB: The role of bone morphogenetic protein signaling in vascular calcification. Bone 141: 115542, 2020

21. Rong S, Zhao X, Jin X, Zhang Z, Chen L, Zhu Y and Yuan W: Vascular calcification in chronic kidney disease is induced by bone morphogenetic protein-2 via a mechanism involving the Wnt/ $\beta$-catenin pathway. Cell Physiol Biochem 34: 2049-2060, 2014.
22. Deng G, Zhang L, Wang C, Wang S, Xu J, Dong J, Kang Q, Zhai X, Zhao Y and Shan Z: AGEs-RAGE axis causes endothelial-to-mesenchymal transition in early calcific aortic valve disease via TGF- $\beta 1$ and BMPR2 signaling. Exp Gerontol 141: 111088, 2020

23. Pescatore LA, Gamarra LF and Liberman M: Multifaceted mechanisms of vascular calcification in aging. Arterioscler Thromb Vasc Biol 39: 1307-1316, 2019.

24. Shanahan CM, Crouthamel MH, Kapustin A and Giachelli CM: Arterial calcification in chronic kidney disease: Key roles for calcium and phosphate. Circ Res 109: 697-711, 2011.

25. Schlieper G, Schurgers L, Brandenburg V, Reutelingsperger C and Floege J: Vascular calcification in chronic kidney disease: An update. Nephrol Dial Transplant 31: 31-39, 2016.

26. Tyson J, Bundy K, Roach C, Douglas H, Ventura V, Segars MF, Schwartz O and Simpson CL: Mechanisms of the osteogenic switch of smooth muscle cells in vascular calcification: WNT signaling, BMPs, mechanotransduction, and endMT. Bioengineering (Basel) 7: 88, 2020.

27. Vellingiri B, Iyer M, Devi Subramaniam M, Jayaramayya K, Siama Z, Giridharan B, Narayanasamy A, Abdal Dayem A and Cho SG: Understanding the role of the transcription factor Sp1 in ovarian cancer: From theory to practice. Int J Mol Sci 21: 1153 , 2020.

28. Sun S, Li T, Jin L, Piao ZH, Liu B, Ryu Y, Choi SY, Kim GR, Jeong JE, Wi AJ, et al: Dendropanax morbifera prevents cardiomyocyte hypertrophy by inhibiting the Sp1/GATA4 pathway. Am J Chin Med 46: 1021-1044, 2018.

29. Wang Y, Cao R, Yang W and Qi B: SP1-SYNE1-AS1-miR-525-5p feedback loop regulates Ang-II-induced cardiac hypertrophy. J Cell Physiol 234: 14319-14329, 2019.

30. Mao Q, Liang X, Wu Y and Lu Y: Resveratrol attenuates cardiomyocyte apoptosis in rats induced by coronary microembolization through SIRT1-mediated deacetylation of p53. J Cardiovasc Pharmacol Ther 24: 551-558, 2019.

31. Kou XX, Hao T, Meng Z, Zhou YH and Gan YH: Acetylated Sp1 inhibits PTEN expression through binding to PTEN core promoter and recruitment of HDAC1 and promotes cancer cell migration and invasion. Carcinogenesis 34: 58-67, 2013.

32. Swingler TE, Kevorkian L, Culley KL, Illman SA, Young DA, Parker AE, Lohi J and Clark IM: MMP28 gene expression is regulated by Spl transcription factor acetylation. Biochem J 427: 391-400, 2010.

33. Torigoe T, Izumi H, Wakasugi T, Niina I, Igarashi T, Yoshida T, Shibuya I, Chijiiwa K, Matsuo K, Itoh $\mathrm{H}$ and Kohno K: DNA topoisomerase II poison TAS-103 transactivates GC-box-dependent transcription via acetylation of Sp1. J Biol Chem 280: 1179-1185, 2005.

34. Hepp MI, Escobar D, Farkas C, Hermosilla VE, Álvarez C, Amigo R, Gutiérrez JL, Castro AF and Pincheira R: A Trichostatin A (TSA)/Sp1-mediated mechanism for the regulation of SALL2 tumor suppressor in Jurkat T cells. Biochim Biophys Acta Gene Regul Mech: May 18, 2018 (Epub ahead of print).

35. Duan X, Zhou Y, Teng X, Tang C and Qi Y: Endoplasmic reticulum stress-mediated apoptosis is activated in vascular calcification. Biochem Biophys Res Commun 387: 694-699, 2009.

36. Ciceri P, Falleni M, Tosi D, Martinelli C, Cannizzo S, Marchetti G, D'Arminio Monforte A, Bulfamante G, Block GA, Messa P and Cozzolino M: Therapeutic effect of iron citrate in blocking calcium deposition in high Pi-calcified VSMC: Role of autophagy and apoptosis. Int J Mol Sci 20: 5925, 2019.

This work is licensed under a Creative Commons Attribution-NonCommercial-NoDerivatives 4.0 International (CC BY-NC-ND 4.0) License. 